\title{
Microwave Enhanced Synthesis of Sulfonated Chitosan-montmorillonite for Effective Removal of Methylene Blue
}

Nur Shazwani Abdul Mubarak

Universiti Sains Malaysia

N.N. Bahrudin

Universiti Sains Malaysia

Ali H. Jawad

Universiti Teknologi MARA

B.H. Hameed

Qatar University

Sumiyyah Sabar ( $\nabla$ sumiyyahs@usm.my )

Universiti Sains Malaysia https://orcid.org/0000-0002-8925-5610

\section{Research Article}

Keywords: Adsorption, Chitosan, Microwave irradiation, Montmorillonite, Sulfonation, Wastewater and Treatment

Posted Date: March 11th, 2021

DOI: https://doi.org/10.21203/rs.3.rs-262124/v1

License: (c) (i) This work is licensed under a Creative Commons Attribution 4.0 International License. Read Full License 
Microwave enhanced synthesis of sulfonated chitosan-montmorillonite for effective removal of methylene blue

Nur Shazwani Abdul Mubarak¹, N.N. Bahrudin',2, Ali H. Jawad³, B.H. Hameed ${ }^{4}$, S. Sabar $^{1 *}$

${ }^{1}$ Chemical Sciences Programme, School of Distance Education (SDE), Universiti Sains Malaysia, 11800 Minden, Penang, Malaysia

${ }^{2}$ Department of Chemistry, Faculty of Science, Universiti Putra Malaysia, 43400 Serdang, Selangor, Malaysia

${ }^{3}$ Faculty of Applied Sciences, Universiti Teknologi MARA, 40450 Shah Alam, Selangor, Malaysia

${ }^{4}$ Department of Chemical Engineering, College of Engineering, Qatar University, P.O. Box: 2713, Doha, Qatar

* Corresponding author. S. Sabar (sumiyyahs@usm.my); Tel.: +6046532284; Fax: +6046576000 . 


\begin{abstract}
In this work, sulfonated chitosan montmorillonite composite (S-CS-MT) beads were synthesized using a microwave irradiation method designed to have a better saving-time procedure. The potency of S-CS-MT as an adsorbent was assessed for the removal of cationic dyes such as methylene blue (MB) from aqueous solution. The batch adsorption experiments indicated that MB adsorption onto S-CS-MT follows the Pseudo-second-order kinetic and Langmuir isotherm model. The maximum extent obtained from the Langmuir isotherm model for MB adsorption was $188.2 \mathrm{mg} \mathrm{g}^{-1}$ at $303 \mathrm{~K}$. The thermodynamic study indicated that the adsorption reaction is favorable and spontaneous. These findings indicated that montmorillonite chitosan grafted with the sulfonate group has the ability and efficacy as biohybrid adsorbent for the adsorption of cationic dyes.
\end{abstract}

\title{
Keywords:
}

Adsorption, Chitosan, Microwave irradiation, Montmorillonite, Sulfonation, Wastewater and Treatment

\section{Introduction}

Dyes are organic compound with aromatic functional groups commonly used in industries like foods, cosmetics, plastics, and textile. Despite that, most dyes are toxic and highly resistant to heat, light and water [1]. Methylene blue (MB), $\mathrm{C}_{16} \mathrm{H}_{18} \mathrm{~N}_{3} \mathrm{SCl}$, is the most studied dye with broad applications as coloring and staining agent. Due to its aggressive nature, $\mathrm{MB}$ has attracted significant attention, which has disharmonious effects on the living and non-living beings, particularly water contamination. Accessibility of high-quality clean water supplies is essential; hence it is obligatory to treat these water contaminations. Plenty of wastewater treatments were invented commercially or lab-scale to prevail with these 
problems. However, adsorption is more reliable and advantageous over other methods due to their low operational cost, low-cost materials, and simple design. Materials are obtainable from numerous sources, for instance, naturally occurring sources from agriculture and industrial waste.

Chitosan (CS) is the most abundantly available natural biopolymer with characteristics such as non-toxic, biocompatibility and biodegradability, has made it the best candidate for dye removal. The presence of amino $\left(-\mathrm{NH}_{2}\right)$ and hydroxyl $(-\mathrm{OH})$ groups on the biopolymer chain function as the coordination sites which provide novel adsorption for various organic dyes [2]. In order to introduce different functional groups onto the polymeric backbone of CS, chemical modification like grafting, crosslinking and impregnation are previously implemented. Grafting is an appealing method because it can increase the density of functional groups on the CS backbone for various applications, such as adsorption. Few types of grafting reaction could occur on CS backbone, which includes grafting with amino [3], carboxyl [4], sulfur [5] and alkyl groups [6]. Grafting ensures that the primary physicochemical and biochemical properties of CS remain unchanged following the chemical characteristics of the functional groups. Recently, Shi et al. [7] synthesized sulfonate CS microspheres by grafting CS with sodium styrene sulfonate (GCS-g-PSSS). The formed free radicals reacted with the monomer through the free radical mechanism to initiate the graft polymerization reaction. The synthesized GCS-g-PSSS possessed a very strong physical adsorption ability with a maximum adsorption capacity of $820.1 \mathrm{mg} \mathrm{g}^{-1}$. Zhang et al. [8] synthesized sulfonated CS for protein adsorption and confirmed that the enhancement of protein binding was due to the sulfate group, which increases the negative charges. On the other hand, Xiang et al. [9] prepared grafted sulfonated CS polymer for the use of proton membrane exchange. They overcome the excessive swelling of S-CS by blending different weight ratios of pure CS. 
Alternatively, attempts have also been made to improve the surface area of CS by combining it with high surface materials, such as clays. Clay minerals have been explored due to their high availability and promising chemical and physical properties. Montmorillonite (MT) is one of the mineral clays used for the physical modification of CS because it is cheap, non-toxic and has a large surface area [10]. Apart from that, they also have high cationic exchange capacity and the possibility of lamellar expansion which offers more versatility in the interaction and intercalation of bulky molecules like CS. MT is negatively charged due to the isomorphous replacement of $\mathrm{Al}^{3+}$ atoms of the octahedra layer for lower valent cations $\left(\mathrm{Mg}^{2+}\right)$ [11]. Wang et al. [10] prepared polyvinyl alcohol sodium alginate-CS-MT nanosheets where MT has two sheets of tetrahedral silica layers and one alumina octahedral layer in the middle. This suggests that the material could support and maintain porous structures allowing an open excess for MB molecules and achieved a maximum adsorption capacity of $137.15 \mathrm{mg} \mathrm{g}^{-1}$. The same researchers also recently synthesized carboxymethyl cellulose CS hydrogel and introduced MT nanosheets as a filler into the system [12]. The MT nanosheet possesses anisotropy characteristics which is a negative charge on surface and positive charge on the edge. The pores are large and abundant, thus facilitating the entrance of macromolecules MB dye into the hydrogels with $283.97 \mathrm{mg} \mathrm{g}^{-1}$ adsorption capacity. Few other articles on CS-MT for MB adsorption have been reported to have high adsorption capacity [13-15]. For the past few years, microwave irradiation (MW) has been a great potential in grafting reactions. Kar et al. [16] successfully synthesized porous CS-MT-hydroxyapatite composite scaffolds by microwave irradiation and gas-foaming method. They have reported improved mechanical property and bioactivity of the synthesized material. Apart from that, da Silva et al. [17] prepared different proportions of CS-MT and stated that microwave irradiation exhibits higher basal spacings than 
conventional heating. On top of that, this technique offers a powerful thermal effect that gives high conversion yield in shorter reaction time through rapid and uniform heating.

This work presents the synthesis of sulfonated chitosan montmorillonite composite (SCS-MT) beads as an adsorbent for MB adsorption. The key parameters affecting MB dye adsorption, such as adsorbent dosage, solution $\mathrm{pH}$, contact time and temperature, were analyzed by batch adsorption experiments. The adsorbent was characterized to elucidate the elemental and surface composition of the adsorbent. A comprehensive study on the adsorption isotherm, kinetic and thermodynamic was executed to establish the nature of the adsorbent material.

\section{Experimental}

\subsection{Materials}

Chitosan flakes (deacetylation degree of 75-85\%, medium MW 190-310 kDa), montmorillonite powder (MT, K10), 4-formyl-1,3-benzene disulfonate salt hydrate (FBSD, $\mathrm{C}_{7} \mathrm{H}_{4} \mathrm{Na}_{2} \mathrm{O}_{7} \mathrm{~S}_{2} . \mathrm{H}_{2} \mathrm{O}, 97 \% \mathrm{w} / \mathrm{v}$ ) and $\mathrm{MB}$ powder (color index no.: 52015 , chemical formula: $\mathrm{C}_{16} \mathrm{H}_{18} \mathrm{ClN}_{3} \mathrm{~S} .3 \mathrm{H}_{2} \mathrm{O}$, molecular weight: $319.85 \mathrm{~g} \mathrm{~mol}^{-1}$ and $\lambda_{\max }: 648 \mathrm{~nm}$ ) were purchased from Sigma-Aldrich, USA. Glacial acetic acid (99.8\%), hydrochloric acid (HCl, 37.0\%) and sodium hydroxide $(\mathrm{NaOH}, 99 \%)$ pellets were obtained from QRec, Malaysia. All chemicals were of analytical grade and used as received. Distilled water was used for dilution and solution preparation.

\subsection{Preparation of S-CS-MT beads}

The preparation of the S-CS-MT beads is summarized in Fig. 1(a). Initially, CS flakes and MT powder with a ratio of 1:1 was added to $5 \% \mathrm{v} / \mathrm{v}$ acetic acid in a $100 \mathrm{~mL}$ conical flask and stirred for $2 \mathrm{~h}$ until the mixture is dissolved completely. Then, $5 \mathrm{~mL}$ of $3 \% \mathrm{v} / \mathrm{v} \mathrm{FBSD}$ 
was added into the solution and stirred for another 15 minutes. Next, the mixed solution was exposed to microwave irradiation in a domestic microwave (Electrolux model EMM2308X) at $800 \mathrm{~W}$ for 3 minutes. The temperature of the reaction was kept below $100{ }^{\circ} \mathrm{C}$ to avoid overheating. After that, the irradiated solution was made into beads by dripping it into $2 \mathrm{M}$ of $\mathrm{NaOH}$ solution using a glass syringe under a constant stirring to avoid beads accumulation. The resultant beads were continuously stirred in $\mathrm{NaOH}$ solution for $2 \mathrm{~h}$ before being washed with copious amounts of distilled water to remove excess $\mathrm{NaOH}$ residual. The washed beads were left soaking in distilled water overnight and dried at $60^{\circ} \mathrm{C}$ dry in an oven for $24 \mathrm{~h}$ before use. The dry weight of the beads was taken as the adsorbent dosage. Fig. 1(b) illustrate the interaction of CS with FBSD and MT interlayers.

\subsection{Physico-chemical characterization}

The surface morphology and elemental composition of the S-CS-MT beads were characterized using a scanning electron microscope coupled with energy dispersive X-ray (SEM-EDX) analyzer (Model Quanta FEG 650 made by FEI, USA). Microstructure properties, such as surface area and porosity analyses, were determined under $\mathrm{N}_{2}$ gas at $77 \mathrm{~K}$ using a physisorption analyzer (Model ASAP 2010, Micrometrics, USA). Fourier transform infrared (FTIR) spectroscopy measurement (Model 2000, Perkin Elmer, USA) was collected between scanning range of $4000-650 \mathrm{~cm}^{-1}$ to verify the functional groups of the modified CS. The point of zero charge $\left(\mathrm{pH}_{\mathrm{pzc}}\right)$ was determined according to a previously reported article [18].

\subsection{Batch adsorption experiments}

Batch adsorption study of MB was conducted in a series $250 \mathrm{~mL}$ Erlenmeyer flasks containing $20 \mathrm{~mL}$ of $\mathrm{MB}$ at different concentrations. Water bath shaker (Memmert, Germany) 
was used to agitate the samples at $303 \mathrm{~K}$ with shaking speed of $200 \mathrm{rpm}$. The adsorption process was performed at different adsorbent dosage $\left(0.2-3.0 \mathrm{~g} \mathrm{~L}^{-1}\right)$, solution $\mathrm{pH}(4-12)$, initial MB concentrations $\left(40-400 \mathrm{mg} \mathrm{L}^{-1}\right)$, contact time $(0-180$ minutes $)$ and temperature $(303-333 \mathrm{~K})$. The desired $\mathrm{pH}$ solution was obtained by adding either $0.1 \mathrm{M}$ of $\mathrm{NaOH}$ or $\mathrm{HCl}$. The MB concentration was measured at different time intervals using a Hach (USA) DR 3900 Direct Reading Spectrophotometer. The amount of MB uptake at equilibrium $\left(q_{e}, \mathrm{mg} \mathrm{g}^{-}\right.$ ${ }^{1}$ ) and the percentage of MB removal, $R(\%)$ were calculated using Eq (1) and (2):

$$
\begin{aligned}
& q_{e}=\frac{\left(C_{o}-C_{e}\right) V}{m} \\
& R=\frac{\left(C_{o}-C_{e}\right)}{C_{o}} \times 100
\end{aligned}
$$

Herein $C_{o}$ is the initial MO dye concentration $\left(\mathrm{mg} \mathrm{L}^{-1}\right) ; C_{e}$ is the equilibrium MO dye concentration $\left(\mathrm{mg} \mathrm{L}^{-1}\right) ; V$ is the volume of MO dye solution (L), and $m$ is the dry mass of the adsorbent $(\mathrm{g})$. All results are reported as an average value where each experiment was conducted in triplicate under identical conditions. The CS, CS-MT and S-CS beads were also produced using the same technique for comparison purposes.

\section{Results and discussion}

\subsection{Physico-chemical characterization}

The SEM-EDX micrographs of S-CS-MT before and after MB adsorption at $10^{4} \times$ magnification is shown in Fig. 2. It can be seen from Fig. 2(a) that the surface of S-CS-MT is rough and heterogeneous. The incorporation of MT clay into the polymer matrix forms flocculated fractions visibly distributed on the adsorbent surface [19]. After MB adsorption (Fig. 2(b)), the S-CS-MT surface becomes smoother and denser due to the accumulation of adsorbed MB molecules. Table 1 summarized the elemental composition of S-CS-MT as obtained by the EDX analysis. The results revealed that the main elements present in the SCS-MT are C, N, and O, which is likely from CS. Other elements such as $\mathrm{Si}, \mathrm{Al}, \mathrm{Mg}, \mathrm{K}$, and 
Fe were identified from the presence of MT in the composite beads [19]. On the other hand, the detection of $\mathrm{S}$ and $\mathrm{Na}$ confirmed the presence of sulfonate groups. The sulfonate groups are important active sites on the adsorbent surface for binding of MB molecules. A similar observation was presented by Sabar et al. [20] for the hydrothermal synthesis of sulfonated CS.

The S-CS-MT surface properties obtained from the $\mathrm{N}_{2}$ adsorption-desorption by the Brunauer, Emmett and Teller (BET) model are tabulated in Table 1. The BET surface area, pore volume and mean pore diameter of S-CS-MT are $2.83 \mathrm{~m}^{2} \mathrm{~g}^{-1}, 3.64 \times 10^{-3} \mathrm{~cm}^{3} \mathrm{~g}^{-1}$ and $5.14 \mathrm{~nm}$, respectively. The BET surface area of S-CS-MT was higher than CS $\left(1.32 \mathrm{~m}^{2} \mathrm{~g}^{-1}\right.$ [20]) but lower than other MT materials [21,22]. The decrease is possibly due to the compact integration of CS into the MT complex structure that leads to pore blocking [23]. The mean pore diameter attained was within 2 to $50 \mathrm{~nm}$, suggesting that S-CS-MT is a mesoporous material. Mesopores adsorbents have shown high adsorption affinity towards MB dye [21].

FTIR spectra of S-CS-MT before and after MB adsorption are presented in Fig. 3 (a-b). As shown in Fig. 3(a), the spectrum of S-CS-MT revealed all three components: CS, FBSD, and MT. The typical CS peaks are located at $3412 \mathrm{~cm}^{-1}$ for O-H and N-H stretching vibrations [24]. There was a slight shift from 3412 to $3439 \mathrm{~cm}^{-1}$, resulting from the overlapping of $\mathrm{NH}$ and $\mathrm{OH}$ stretching vibration of $\mathrm{CS}$ with the $\mathrm{OH}$ groups of silanol and $\mathrm{MT}$ [25]. The $\mathrm{S}=\mathrm{O}$ stretching vibration from the sulfonic group was observed at peaks 1384-1385 $\mathrm{cm}^{-1}$. The results also suggested that some of the hydrogen bonds in the CS structure are demolished, but new ones are formed between the functional groups of CS and Al-OH/Si-OH of MT. The peak at $1040 \mathrm{~cm}^{-1}$ indicates Si-O-Si characteristics, which corresponds to the MT structure [26]. Other related peaks to CS, such as at $1385 \mathrm{~cm}^{-1}$ (corresponds to -NH deformation and - $\mathrm{CN}$ vibration stretching), remained unchanged upon modification. After MB adsorption (Fig. 3(b)), the strong Si-O bands at $1031 \mathrm{~cm}^{-1}$ of S-CS-MT shifted to 1041 
$\mathrm{cm}^{-1}$. The peak was also shifted at $3412 \mathrm{~cm}^{-1}$ (NH and $\mathrm{OH}$ stretching), confirming that the $\mathrm{S}$ CS-MT was involved in the adsorption process.

\subsection{Adsorption studies}

The comparison of CS, CS-MT, S-CS and S-CS-MT for MB adsorption is illustrated in Fig. 4. Pure CS showed the lowest MB uptake of $0.66 \mathrm{mg} \mathrm{g}^{-1}$. As for CS-MT, the MB uptake gradually increases, which indicates that there are adsorption sites available on the surface of adsorbent to remove MB dye. The rapid increase was recorded for S-CS, and it reached equilibrium after 75 minutes. A slight decrease was seen after 120 minutes, indicating that desorption of MB dye occurs due to the repulsion between the adsorbed species. Overall, SCS-MT showed the highest MB uptake of $2.67 \mathrm{mg} \mathrm{g}^{-1}$ with removal percentage of $>95 \%$ after $3 \mathrm{~h}$ of contact time. The synergistic effect of broadened pores and electrostatic interaction between the functional group of MB dye and the sulfonated groups of CS plays a vital role in MB uptake. The increased pores allow the penetration of MB dye into the interlayer space of the S-CS-MT composite. The findings signify the potential of S-CS-MT as an effective adsorbent for the removal of MB dye or other similar cationic dyes.

The optimum adsorbent dosage of S-CS-MT was determined by varying the amounts of S-CS-MT ranging from $0.2-3.0 \mathrm{~g} \mathrm{~L}^{-1}$ and its effect on the adsorption capacity, and percent removal is presented in Fig. 5. The figure shows that by increasing the adsorbent dosage, the percentage of MB removal was also increased. The removal efficiency improved tremendously as the amount of S-CS-MT increased before the saturation level was reached at a dose greater than $1.5 \mathrm{~g} \mathrm{~L}^{-1}$. It can be due to the multiplication of the adsorbent surface and the availability of more adsorption sites. On the other hand, the MB uptake tends to decrease from 5.77 to $1.01 \mathrm{mg} \mathrm{g}^{-1}$ with increasing adsorbent dosage. This is due to the unsaturation of sorption sites through the sorption process on overdosing of the adsorbent at fixed MB 
concentration and volume [27]. Moreover, aggregation may occur at high adsorbent dosage that leads to a decrease in total surface area of the sorbent and increase in the length of the diffusion path [27]. Therefore, $1.1 \mathrm{~g} \mathrm{~L}^{-1}$ was selected as the optimum adsorbent dosage of SCS-MT for MB dye and was used for further analysis.

The $\mathrm{pH}_{\mathrm{pzc}}$ value and the effect $\mathrm{pH}$ solution on MB adsorption by S-CS-MT has been observed and reported in Fig. 6 (a) and (b), respectively. In most cases, the pH solution is expected to influence the adsorption capacity of the adsorbate since it affects both the adsorbent surface binding sites and the ionization mechanism of the adsorbate. However, Fig. 6(b) showed that the $\mathrm{pH}$ solution did not influence the adsorption performance of S-CS-MT due to the buffering effect of the adsorbent [28]. The average MB uptake from $\mathrm{pH} 4$ to 12 was $2.56 \mathrm{mg} \mathrm{g}^{-1}$, and the $\mathrm{pH}_{\mathrm{pzc}}$ calculated for S-CS-MT was 7.2. Generally, the adsorbent can be classified as negatively charged at $\mathrm{pH}>\mathrm{pH}_{\mathrm{pzc}}$. At this point, the electrostatic interaction improved between the negatively charged S-CS-MT and the MB dye cations. At $\mathrm{pH}<\mathrm{pH}_{\mathrm{pzc}}$, the surface of adsorbent is positively charged where it resulted in electrostatic repulsion between the MB dye and the S-CS-MT surface. However, adsorption happens at acidic $\mathrm{pH}$ owing to the $\pi-\pi$ interactions between the S-CS-MT and MB dye. Further experiments were conducted at ambient $\mathrm{pH}$ of $\mathrm{MB}(\mathrm{pH}$ 6) since it lies within the optimal $\mathrm{pH}$ range.

The effect of initial MB concentration and contact time on MB uptake by S-CS-MT is shown in Fig. 7. The abundance of empty adsorption sites was rapidly filled with MB molecules within the first 15 minutes. At low MB concentration, the adsorption was fast and reached equilibrium after 30 minutes. However, higher $\mathrm{MB}$ concentrations require a longer time to reach the equilibrium state. This is because the MB molecules require more time to overcome the mass resistance to diffuse into the inner surface of the adsorbent [28]. The equilibrium state was attained at 60 minutes for MB concentration of 200 to $400 \mathrm{mg} \mathrm{L}^{-1}$. The MB uptake showed an increment from 15.3 to $141.2 \mathrm{mg} \mathrm{g}^{-1}$ with increased initial MB dye 
concentration from 40 to $400 \mathrm{mg} \mathrm{L}^{-1}$. The driving force of the pressure gradient can be overcome at high concentrations, thus enhancing the transport of MB dye molecules to the adsorption sites [29].

\subsection{Adsorption kinetics}

In order to describe the reaction rate and mechanism of MB adsorption onto S-CS-MT, the non-linear pseudo-first-order (PFO) and pseudo-second-order (PSO) models were fitted to the experimental data. The PFO and PSO models are defined as Eq (3) [30] and Eq (4) [31], respectively:

$$
\begin{aligned}
& q_{t}=q_{e}\left(1-\exp ^{-k_{1} t}\right) \\
& q_{t}=\frac{q_{e}^{2} k_{2} t}{1+q_{e} k_{2} t}
\end{aligned}
$$

where $q_{e}$ and $q_{t}$ are the adsorption capacity of $\mathrm{MB}$ dye $\left(\mathrm{mg} \mathrm{g}^{-1}\right)$ at equilibrium and at different time $t$, respectively. The $k_{1}\left(\mathrm{~min}^{-1}\right)$ and $k_{2}\left(\mathrm{~g} \mathrm{mg}^{-1} \mathrm{~min}^{-1}\right)$ are the PFO and PSO rate constant, respectively.

The coefficient of determination $\left(R^{2}\right)$ normalized standard deviation (NSD) and average relative error (ARE) was evaluated to determine the best-fit kinetic model. The equations for these functions are defined below [32]:

$$
\begin{aligned}
& R^{2}=1-\frac{\sum_{n=1}^{n}\left(q_{t, \mathrm{exp}}-q_{t, c a l}\right)^{2}}{\sum_{n=1}^{n}\left(q_{t, c a l}-\overline{q_{t, c a l}}\right)^{2}} \\
& N S D=100 \times{\sqrt{\frac{1}{n-1} \sum_{i=1}^{n}\left[\frac{q_{t, \exp }-q_{t, c a l}}{q_{t, \text { exp }}}\right]^{2}}}^{2} \\
& A R E=\frac{100}{n} \sum_{i=1}^{n}\left[\frac{q_{t, \exp }-q_{t, c a l}}{q_{t, \exp }}\right]
\end{aligned}
$$


where $q_{t, \exp }$ and $q_{t, c a l}$ are the experimental- and model-predicted adsorption capacity of MB

dye $\left(\mathrm{mg} \mathrm{g}^{-1}\right)$ at time $t$, respectively, and $n$ is the number of experimental data points. The bestfit model was chosen based on its high $R^{2}$ and low NSD and ARE values.

The comparison of the kinetic data is displayed in Fig. 7 and summarized in Table 2. Based on the calculated values, the PSO model showed lower NSD and ARE values than the PFO model. The finding suggests that chemisorption is the potential rate-controlling step and that the adsorption process involves the sharing or exchange of electrons between the adsorbate and the adsorbent [33]. The PSO model has been reported as the best-fit model to describe MB adsorption by other CS-based adsorbents [15, 34].

\subsection{Adsorption isotherms}

Adsorption isotherms are important to optimize the use of the adsorbent and to explain its interaction with the contaminants [35]. The experimental data were fitted to three isothermal equilibrium models which are Langmuir, Freundlich and Temkin. The non-linear form of Langmuir, Freundlich and Temkin isotherm models are given by Eq (8), (9) and (10) [32], respectively:

$$
\begin{aligned}
& q_{e}=\frac{q_{m} K_{L} C_{e}}{1+K_{L} C_{e}} \\
& q_{e}=K_{F} C_{e}^{1 / n} \\
& q_{e}=B \ln \left(A C_{e}\right)
\end{aligned}
$$

where $q_{m}$ is the maximum adsorption capacity of the adsorbent $\left(\mathrm{mg} \mathrm{g}^{-1}\right), K_{L}$ is the Langmuir constant related to the adsorption energy $\left(\mathrm{L} \mathrm{mg}^{-1}\right), K_{F}$ is the Freundlich constant related to the bonding energy $\left(\mathrm{L} \mathrm{g} \mathrm{g}^{-1}\right), n$ is the adsorption intensity and/or surface heterogeneity, $B=R T / b$ and corresponded to adsorption enthalpy, $R$ is the gas constant $\left(8.314 \times 10^{-3} \mathrm{~kJ} \mathrm{~mol}^{-1} \mathrm{~K}^{-1}\right)$, T 
is the absolute temperature $(\mathrm{K}), b$ is the Temkin constant related to the adsorption heat $(\mathrm{kJ}$ $\left.\mathrm{mol}^{-1}\right)$, and $A$ is the maximum binding energy at equilibrium $\left(\mathrm{L} \mathrm{g}^{-1}\right)$. The best-described isotherm model was selected based on the $R^{2}$ and the residual root-mean-squared error (RMSE), expressed by:

$$
\begin{aligned}
& R^{2}=1-\frac{\sum_{n=1}^{n}\left(q_{e, \exp }-q_{e, c a l}\right)^{2}}{\sum_{n=1}^{n}\left(q_{e, \exp }-\overline{q_{e, c a l}}\right)^{2}} \\
& R M S E=\sqrt{\frac{1}{n-1} \sum_{n=1}^{n}\left(q_{e, \exp }-q_{e, c a l}\right)^{2}}
\end{aligned}
$$

where $q_{e, \exp }$ and $q_{e, c a l}$ are the experimental- and model-predicted adsorption capacity $\left(\mathrm{mg} \mathrm{g}^{-1}\right)$ at equilibrium, respectively, and $n$ is the number of experimental data points.

The adsorption isotherm plots, and the calculated data are displayed and listed in Fig. 8 and Table 3, respectively. The results indicated that the Langmuir isotherm model has the highest $R^{2}$ and lowest RMSE values than other isotherm models. The good fitting of the Langmuir isotherm model implies monolayer coverage which proceeds over a surface comprising a finite number of adsorption sites. Apart from that, uniform strategies of adsorption without transmigration of adsorbate in the surface plane also plays a part [36]. Additionally, the $q_{m}$ values decreased with the increase in the adsorption temperature. The lower temperature was more favorable for MB adsorption with $q_{m}$ values of 188.2, 185.7, and $123.5 \mathrm{mg} \mathrm{g}^{-1}$ at 303,313 , and $323 \mathrm{~K}$ respectively. The values are comparable and somewhat better than other CS-based sorbent reported in the literature. Table 4 summarize the comparison of the $q_{m}$ values obtained for MB adsorption by S-CS-MT versus other reported studies on various CS-based sorbent. 


\subsection{Diffusion models}

Weber and Morris model postulated that the adsorption process involves four main steps which are bulk diffusion, film diffusion, intraparticle diffusion or pore diffusion, and chemical reaction via ion exchange, complexation and/or chelation [36]. Dye adsorption is regulated primarily by either the liquid phase or the intraparticle mass transport rates [35]. The intraparticle diffusion model that was suggested by Weber and Morris [41] is defined by $\mathrm{Eq}(13)$ :

$$
q_{t}=k_{i d} t^{1 / 2}+C
$$

where $k_{i d}$ is the intraparticle diffusion rate constant $\left(\mathrm{mg} \mathrm{g}^{-1} \mathrm{~min}^{-1 / 2}\right)$, and $C$ corresponds to the boundary layer effect $\left(\mathrm{mg} \mathrm{g}^{-1}\right)$. The $k_{i d}$ values were determined from the linear plot of $q_{t}$ versus $t^{1 / 2}$ (Figure not shown). As presented in Table 5, the increase in MB concentration shows an increase in $k_{i d}$ and $C$ values of the intraparticle diffusion model. The findings could be explained by the greater boundary layer and mass transfer around the adsorbent particle with concentration.

The Boyd model was applied to differentiate between the film and intraparticle diffusion. The model is generally given in its linearized form by Eq (14) [42]:

$$
\ln \left(1-\frac{q_{t}}{q_{e}}\right)=-k_{f d} t
$$

where $k_{f d}$ is the liquid film diffusion constant $\left(\mathrm{min}^{-1}\right)$. The parameter is obtained from the gradient of the linear plots of $\ln \left(1-q_{t} / q_{e}\right)$ versus $t$ (Figure not shown). According to the calculated results (Table 5), the correlation coefficients of film diffusion are more linear than the intraparticle diffusion. The finding suggests that the MB diffusion onto the adsorbent surface was regulated by film diffusion [36]. 


\subsection{Thermodynamic functions}

The thermodynamic functions of MB dye at different temperatures was studied by calculating the standard Gibbs free energy $\left(\Delta G^{o}\right)$, standard enthalpy $\left(\Delta H^{o}\right)$, and standard entropy $\left(\Delta S^{o}\right)$ by the following equations [43]:

$$
\begin{aligned}
& \ln K_{d}=\frac{\Delta S^{\circ}}{R}-\frac{\Delta H^{\circ}}{R T} \\
& \Delta G^{\circ}=-R T \ln K_{d} \\
& K_{d}=\frac{q_{e}}{C_{e}}
\end{aligned}
$$

where $K_{d}$ is the equilibrium constant, $R$ is the universal gas constant $\left(8.314 \mathrm{~J} \mathrm{~K}^{-1} \mathrm{~mol}^{-1}\right)$, and $T$ is the solution temperature (K). The values of $\Delta H^{o}$ and $\Delta S^{o}$ were calculated from the gradient and intercept of van't Hoff plot, and the values are summarized in Table 6. The negative values of $\Delta G^{\mathrm{o}}$ indicate that the adsorption is spontaneous and favorable, which allows the regeneration of energy during the process [44]. The less negative $\Delta G^{\circ}$ values with increasing temperature suggest that the adsorption was less favorable at higher temperatures. On the other hand, the $\Delta H^{\mathrm{o}}$ value $\left(-52.3 \mathrm{~kJ} \mathrm{~mol}^{-1}\right)$ signified that the adsorption is exothermic in nature. The findings of the study imply that H-bonding and dipole interaction play a greater role in the adsorption process, rather than the diffusion of the dye species into the internal pores of the adsorbent [45]. The negative value of $\Delta S^{\circ}\left(-149.4 \mathrm{~J} \mathrm{~mol}^{-1} \mathrm{~K}^{-1}\right)$ infers a decrease in the randomness of MB dye at the solid/liquid interface during the adsorption process. The movements of dye molecules increased as the temperature increases, contributing to the desorption of dye species from solid to the liquid phase. As a result, the amount of MB adsorbed onto the S-CS-MT surface decreased at higher temperature [45].

\subsection{Adsorption mechanism}

The synthesized S-CS-MT has multifunction active sites for capturing MB molecules on its polymeric backbone. These active sites can offer various possible interactions with MB 
dye molecules, as illustrated in Fig 9. Electrostatic interaction is one of the attraction forces between the negative functional groups of the S-CS-MT $\left(-\mathrm{SO}_{3^{-}},-\mathrm{O}^{-}\right)$with the positive charge $\left(\mathrm{C}=\mathrm{HN}^{+}\right)$of $\mathrm{MB}$ dye molecules. A similar observation was reported for capturing of $\mathrm{MB}$ molecules by CS-epichlorohydrin/zeolite composite [27]. Other possible interactions are $n-\pi$ and $\pi-\pi$ interactions. The $n-\pi$ interaction can occur between the lone pair electrons of the oxygen $(\mathrm{O})$ and nitrogen $(\mathrm{N})$ atoms on S-CS-MT with the aromatic rings of the MB molecules. In contrast, the $\pi-\pi$ interaction occurs between the aromatic rings of the sulfonated groups on S-CS-MT with the aromatic rings of MB molecules. Likewise, Yan et al., [46] suggested the same interaction for MB adsorption by CS crosslinked graphene oxide//lignosulfonate composite. Finally, possible $\mathrm{H}$-bonding between the free $\mathrm{H}$ atom on the polymeric backbone of S-CS-MT with the N atom of MB dye.

\section{Conclusion}

Sulfonated chitosan-montmorillonite (S-CS-MT) composite beads were successfully prepared by microwave irradiation. The surface morphology, elemental composition and microstructure properties were confirmed by the SEM-EDX, FTIR and BET analysis. The adsorbent produced was found to improve MB adsorption with a maximum adsorption capacity substantially, $q_{m}$ of $188.2 \mathrm{mg} \mathrm{g}^{-1}$ at $303 \mathrm{~K}$. The non-linear kinetics and adsorption isotherm models showed that the experimental data fitted well with the pseudo-second-order and the Langmuir models, respectively. Thermodynamics studies revealed that MB adsorption onto S-CS-MT is spontaneous and exothermic. Overall, S-CS-MT has the potential to be a promising adsorbent since it can be easily synthesized with good adsorption performance for the removal of cationic dye, particularly MB dye. 


\section{Declarations}

Funding: S. Sabar has received research support from Ministry of Higher Education (MOHE), Malaysia (203/PJJAUH/6711445). Nur Shazwani Abdul Mubarak has received a fellowship from Universiti Sains Malaysia (USM).

Conflicts of interest/Competing interests: The authors have no conflicts of interest to declare that are relevant to the content of this article.

Availability of data and material (data transparency): The datasets generated during and/or analysed during the current study are available from the corresponding author on reasonable request.

Code availability (software application or custom code): Not applicable

\section{Authors' contributions:}

Nur Shazwani Abdul Mubarak: Formal analysis, Writing - Original Draft, Visualization N.N. Bahrudin: Formal analysis, Investigation, Data Curation, Methodology, Validation Ali H. Jawad: Validation, Writing - Review \& Editing,

B.H. Hameed: Validation, Writing - Review \& Editing, Funding acquisition

S. Sabar: Conceptualization, Methodology, Validation, Resources, Writing - Review \& Editing, Visualization, Supervision, Project administration, Funding acquisition

\section{Acknowledgement}

The authors would like to acknowledge the Ministry of Higher Education (MOHE), Malaysia, for supporting this project under the Fundamental Research Grant Scheme (FRGS) (203/PJJAUH/6711445). Nur Shazwani Abdul Mubarak would like to thank Universiti Sains Malaysia (USM) for the fellowship under the USM Fellowship program. The authors also would like to thank School of Distance Education, School of Chemical Sciences, School of Physics and Centre for Global Archaeological Research, USM for its research facilities. 


\section{References}

[1] Mok CF, Ching YC, Muhamad F, Abu Osman NA, Hai ND, \& Che Hassan CR (2020). Adsorption of Dyes Using Poly(vinyl alcohol) (PVA) and PVA-Based Polymer Composite Adsorbents: A Review. J Polym Environ. 28: 775-793.

[2] Jawad AH, Mubarak NSA, and Abdulhameed AS (2020) Hybrid Crosslinked

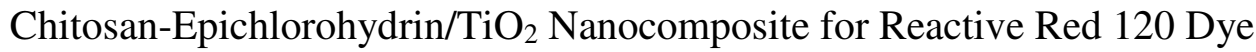
Adsorption: Kinetic, Isotherm, Thermodynamic, and Mechanism Study. J Polym Environ 28: 624-637.

[3] Medeiros Borsagli FGL, Carvalho IC, \& Mansur HS (2018) Amino acid-grafted and $\mathrm{N}$-acylated chitosan thiomers: Construction of 3D bio-scaffolds for potential cartilage repair applications. Int J Biol Macromol 114: 270-282.

[4] Anirudhan TS, \& Rijith S (2012) Synthesis and characterization of carboxyl terminated poly(methacrylic acid) grafted chitosan/bentonite composite and its application for the recovery of uranium(VI) from aqueous media. J Environ Radioact 106: 8-19.

[5] Chatterjee S, Chatterjee T, Lim SR, \& Woo SH (2011) Adsorption of a cationic dye, methylene blue, on to chitosan hydrogel beads generated by anionic surfactant gelation. Environ Technol 32: 1503-1514.

[6] Iordache ML, Dodi G, Hritcu D, Draganescu D, Chiscan O, \& Popa MI (2018) Magnetic chitosan grafted (alkyl acrylate) composite particles: Synthesis, characterization and evaluation as adsorbents. Arabian J Chem 11:1032-1043.

[7] Shi H, Dong C, Yang Y, Han Y, Wang F, Wang C, \& Men J (2020) Preparation of sulfonate chitosan microspheres and study on its adsorption properties for methylene blue. Int J Biol Macromol 163: 2334-2345. 
[8] Zhang X, \& Sun J (2020) Synthesis, Characterization, and Properties of Sulfonated Chitosan for Protein Adsorption. Int J Polym Sci 2020: 9876408.

[9] Xiang Y, Yang M, Guo Z, \& Cui Z (2009) Alternatively chitosan sulfate blending membrane as methanol-blocking polymer electrolyte membrane for direct methanol fuel cell. J Membr Sci 337: 318-323.

[10] Wang W, Zhao Y, Bai H, Zhang T, Ibarra-Galvan V, \& Song S (2018) Methylene blue removal from water using the hydrogel beads of poly(vinyl alcohol)-sodium alginate-chitosan-montmorillonite. Carbohydr Polym 198: 518528.

[11] Nesic AR, Velickovic SJ, \& Antonovic DG (2012) Characterization of chitosan/montmorillonite membranes as adsorbents for Bezactiv Orange V-3R dye. J Hazard Mater 209: 256-263.

[12] Wang W, Ni J, Chen L, Ai Z, Zhao Y, \& Song S (2020) Synthesis of carboxymethyl cellulose-chitosan-montmorillonite nanosheets composite hydrogel for dye effluent remediation. Int J Biol Macromol 165: 1-10.

[13] Kang S, Zhao Y, Wang W, Zhang T, Chen T, Yi H, Song S (2018) Removal of methylene blue from water with montmorillonite nanosheets/chitosan hydrogels as adsorbent. Appl Surf Sci 448: 203-211.

[14] El-Kousy SM, El-Shorbagy HG, \& El-Ghaffar MAA (2020) Chitosan/montmorillonite composites for fast removal of methylene blue from aqueous solutions. Mater Chem Phys 254: 123236.

[15] Zhao Y, Kang S, Qin L, Wang W, Zhang T, Song S, \& Komarneni S (2020) Selfassembled gels of Fe-chitosan/montmorillonite nanosheets: Dye degradation by the synergistic effect of adsorption and photo-Fenton reaction. Chem Eng J 379: 122322. 
[16] Kar S, Kaur T, \& Thirugnanam A (2016) Microwave-assisted synthesis of porous chitosan-modified montmorillonite-hydroxyapatite composite scaffolds. Int J Biol Macromol 82: 628-636.

[17] da Silva JC, França D, Rodrigues F, Oliveira DM, Trigueiro P, Silva Filho E, \& Fonseca M (2021) What happens when chitosan meets bentonite under microwave-assisted conditions? Clay-based hybrid nanocomposites for dye adsorption. Colloids Surf A 609: 125584.

[18] Jawad AH, Mamat NH, Hameed B, \& Ismail K (2019) Biofilm of cross-linked chitosan-ethylene glycol diglycidyl ether for removal of reactive red 120 and methyl orange: Adsorption and mechanism studies J Environ Chem Eng 7: 102965.

[19] M Gierszewska, E Jakubowska, \& E Olewnik-Kruszkowska (2019) Effect of chemical crosslinking on properties of chitosan-montmorillonite composites. Polym Test 77: 105872.

[20] Sabar S, Aziz HA, Yusof N, Subramaniam S, Foo K, Wilson L, \& Lee H (2020) Preparation of sulfonated chitosan for enhanced adsorption of methylene blue from aqueous solution. React Funct Polym 151: 104584.

[21] Karaca S, Önal EÇ, Açışlı Ö, \& Khataee A (2021) Preparation of chitosan modified montmorillonite biocomposite for sonocatalysis of dyes: Parameters and degradation mechanism. Mater Chem Phys 260: 124125.

[22] Sirajudheen P, \& Meenakshi S (2020) Lanthanum (III) incorporated chitosanmontmorillonite composite as flexible material for adsorptive removal of azo dyes from water. Mater Today Proc 27: 318-326. 
[23] Monvisade P, \& Siriphannon P (2009) Chitosan intercalated montmorillonite: Preparation, characterization and cationic dye adsorption. Appl Clay Sci 42: 427431.

[24] Sun Z, Shi C, Wang X, Fang Q, \& Huang J (2017) Synthesis, characterization, and antimicrobial activities of sulfonated chitosan. Carbohydr Polym 155: 321328.

[25] Vanamudan A \& Pamidimukkala P (2015) Chitosan, nanoclay and chitosannanoclay composite as adsorbents for Rhodamine-6G and the resulting optical properties. Int J Biol Macromol 74: 127-135.

[26] Guo Y, Ge X, Guan J, Wu L, Zhao F, Li H, Chen A (2016) A novel method for fabricating hybrid biobased nanocomposites film with stable fluorescence containing CdTe quantum dots and montmorillonite-chitosan nanosheets. Carbohydr Polym 145: 13-19

[27] Alghamdi AA, Al-Odayni AB, Saeed WS, Al-Kahtani A, Alharthi FA, \& Aouak T (2019) Efficient adsorption of lead (II) from aqueous phase solutions using polypyrrole-based activated carbon. Mater 12:12

[28] Jawad AH, Abdulhameed AS, Reghioua A, \& Yaseen ZM (2020) Zwitterion composite chitosan-epichlorohydrin/zeolite for adsorption of methylene blue and reactive red 120 dyes. Int J Biol Macromol 163: 756-765.

[29] Jawad AH, Mubarak NSA, \& Abdulhameed AS (2020) Tunable Schiff's basecross-linked chitosan composite for the removal of reactive red 120 dye: adsorption and mechanism study. Int J Biol Macromol 142: 732-741.

[30] Lagergren S (1898) Zur theorie der sogenannten adsorption gelöster stoffe, Kungliga Svenska Vetenskapsakademiens, Handlingar, 24: 1-39. 
[31] Ho Y, \& McKay G (1998) A comparison of chemisorption kinetic models applied to pollutant removal on various sorbents. Process Saf Environ Prot 76: $332-340$.

[32] Foo KY, \& Hameed BH (2010) Insights into the modeling of adsorption isotherm systems. Chem Eng J 156: 2-10.

[33] Rezakazemi M, \& Shirazian S (2019) Lignin-chitosan blend for methylene blue removal: Adsorption modeling. J Mol Liq 274: 778-791.

[34] Jyothi MS, Angadi VJ, Kanakalakshmi TV, Padaki M, Geetha BR, \& Soontarapa K (2019) Magnetic nanoparticles impregnated, cross-linked, porous chitosan microspheres for efficient adsorption of methylene blue from pharmaceutical waste water. J Polym Environ, 27: 2408-2418

[35] Hosseini S, Khan MA, Malekbala MR, Cheah W, \& Choong TSY (2011) Carbon coated monolith, a mesoporous material for the removal of methyl orange from aqueous phase: Adsorption and desorption studies, Chem Eng J 171: 1124-1131.

[36] Hameed BH, Din ATM, \& Ahmad AL (2007) Adsorption of methylene blue onto bamboo-based activated carbon: kinetics and equilibrium studies. J Hazard Mater. 141: 819-825.

[37] Albadarin AB, Collins MN, Naushad M, Shirazian S, Walker G, \& Mangwandi C (2017) Activated lignin-chitosan extruded blends for efficient adsorption of methylene blue. Chem Eng J 307: 264-272.

[38] Marrakchi F, Khanday W, Asif M, \& Hameed B (2016) Cross-linked chitosan/sepiolite composite for the adsorption of methylene blue and reactive orange 16. Int J Biol Macromol 93: 1231-1239. 
[39] Fan L, Luo C, Li X, Lu F, Qiu H, \& Sun M (2012) Fabrication of novel magnetic chitosan grafted with graphene oxide to enhance adsorption properties for methyl blue. J Hazard Mater 215: 272-279.

[40] Marrakchi F, Ahmed M, Khanday W, Asif M, \& Hameed B (2017) Mesoporousactivated carbon prepared from chitosan flakes via single-step sodium hydroxide activation for the adsorption of methylene blue. Int J Biol Macromol 98: 233-239.

[41] Weber WJ \& Morris JC (1963) Kinetics of adsorption on carbon from solution. J Sanit Eng Div 89: 31-60.

[42] Boyd G, Adamson A, \& Myers Jr L (1947) The exchange adsorption of ions from aqueous solutions by organic zeolites. II. Kinetics1. J Am Chem Soc 69: 28362848.

[43] Chen Y, Long W, \& Xu H (2019) Efficient removal of Acid Red 18 from aqueous solution by in-situ polymerization of polypyrrole-chitosan composites. J Mol Liq 287: 110888.

[44] Kazemi J, \& Javanbakht V (2020) Alginate beads impregnated with magnetic Chitosan@ Zeolite nanocomposite for cationic methylene blue dye removal from aqueous solution. Int J Biol Macromol 154: 1426-1437.

[45] Banerjee S, \& Chattopadhyaya M (2017) Adsorption characteristics for the removal of a toxic dye, tartrazine from aqueous solutions by a low cost agricultural by-product. Arabian J Chem 10: S1629-S1638.

[46] Yan M, Huang W, \& Li Z (2019) Chitosan cross-linked graphene oxide/lignosulfonate composite aerogel for enhanced adsorption of methylene blue in water. Int J Biol Macromol 136 927-935. 


\section{Figures}

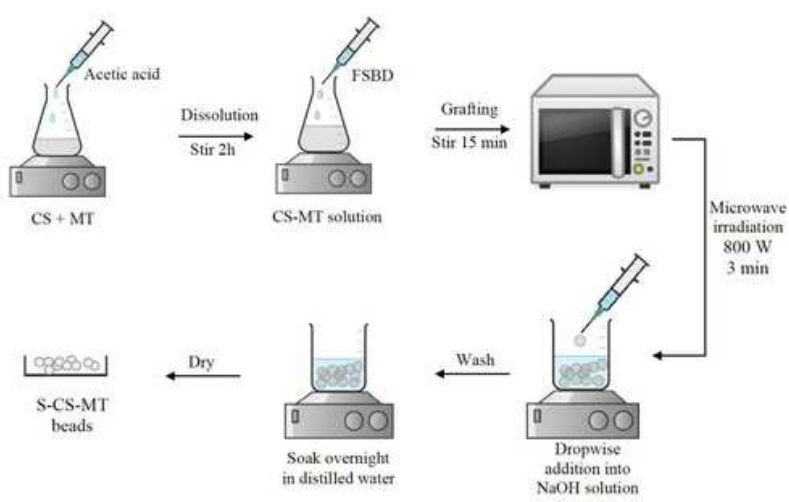

(a)

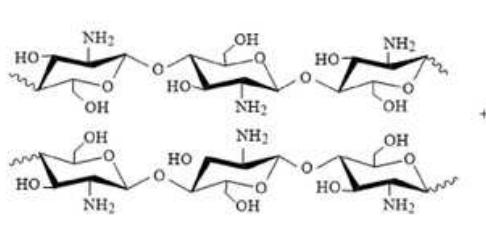

cs

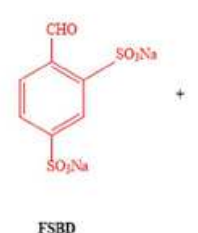

FSBD
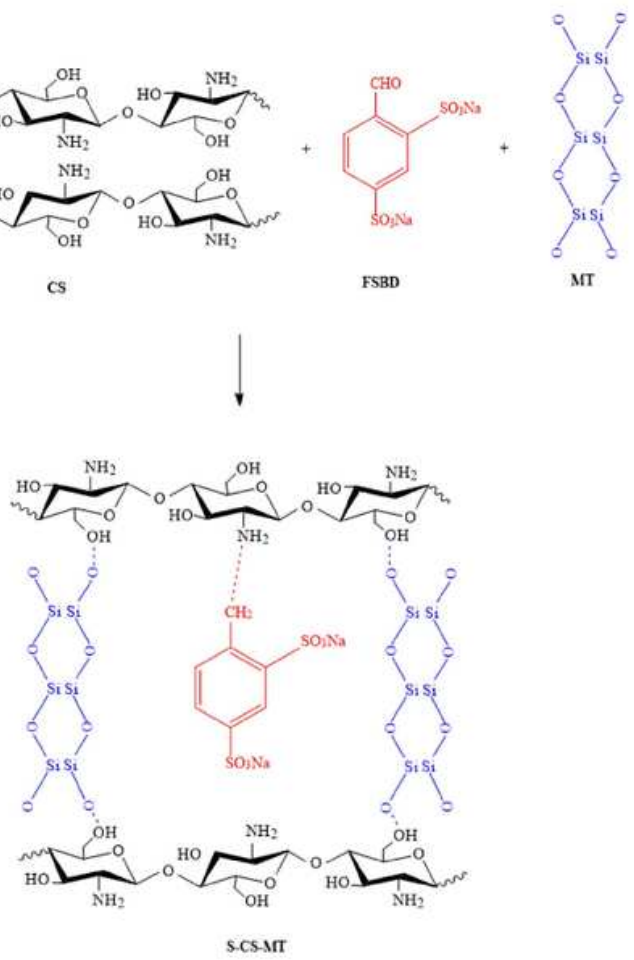

(b)

\section{Figure 1}

Schematic diagram of (a) the step-by-step preparation of S-CS-MT beads and (b) the interaction involved.
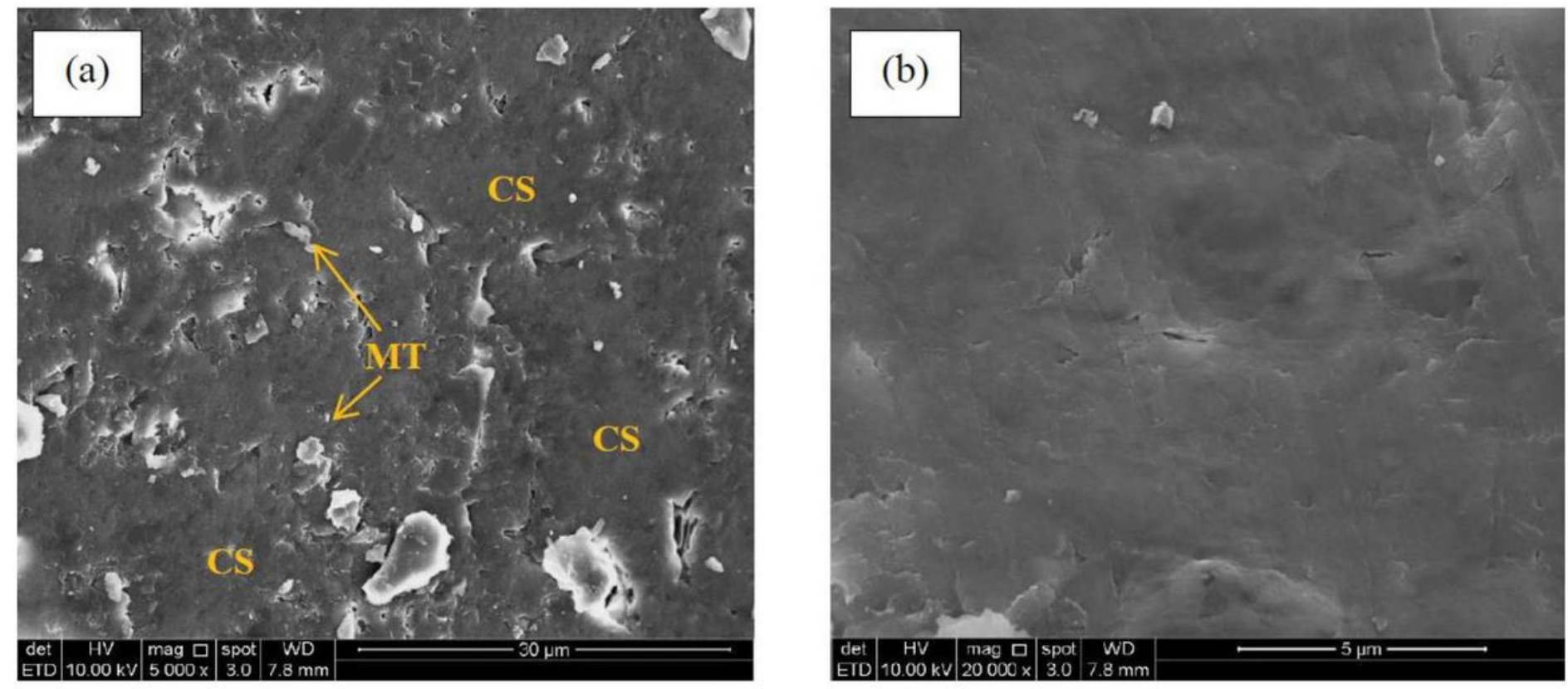

Figure 2 
SEM images of (a) S-CS-MT and (b) S-CS-MT after MB adsorption at $104 \times$ magnification.

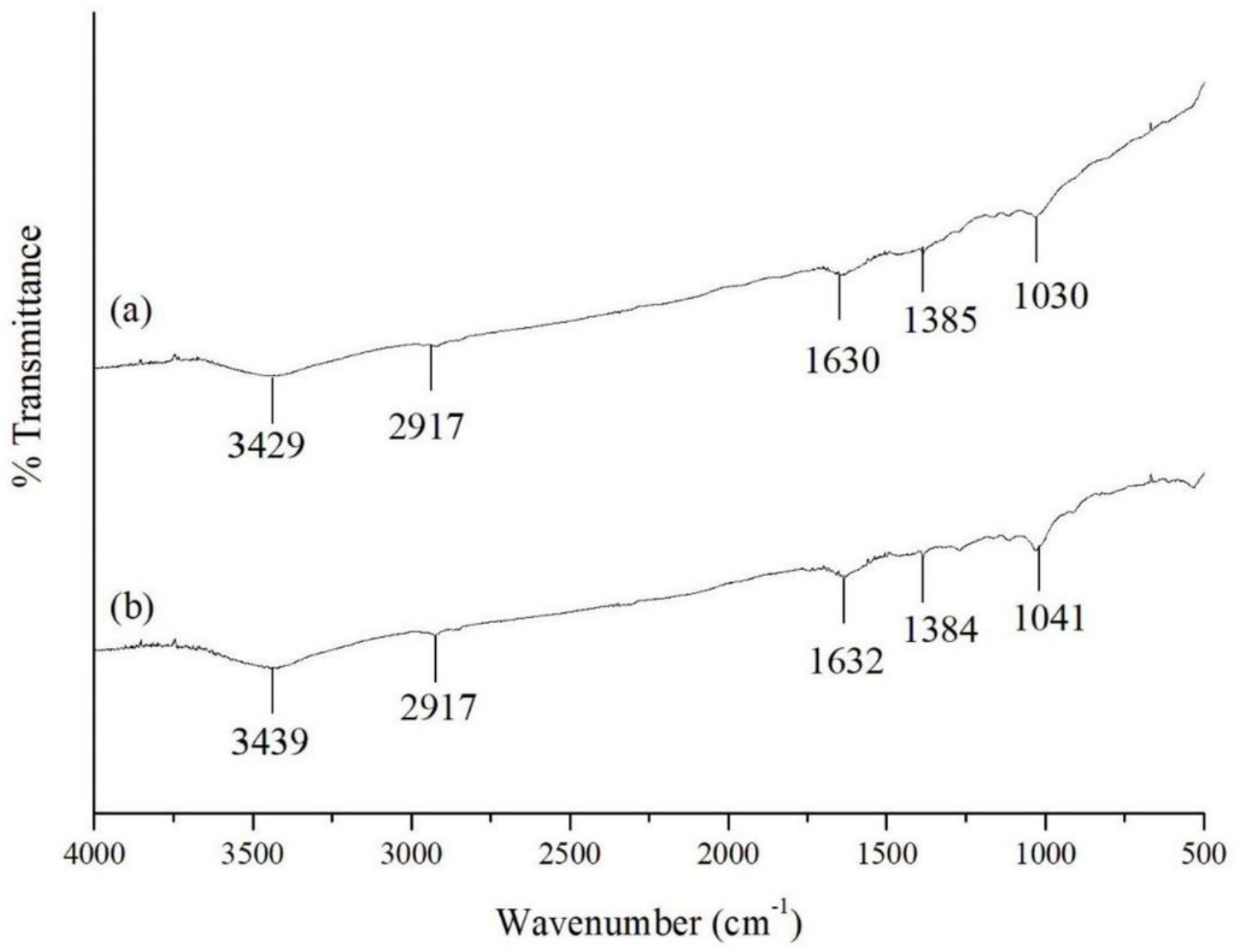

Figure 3

FTIR spectra of (a) S-CS-MT and (b) S-CS-MT after MB adsorption. 


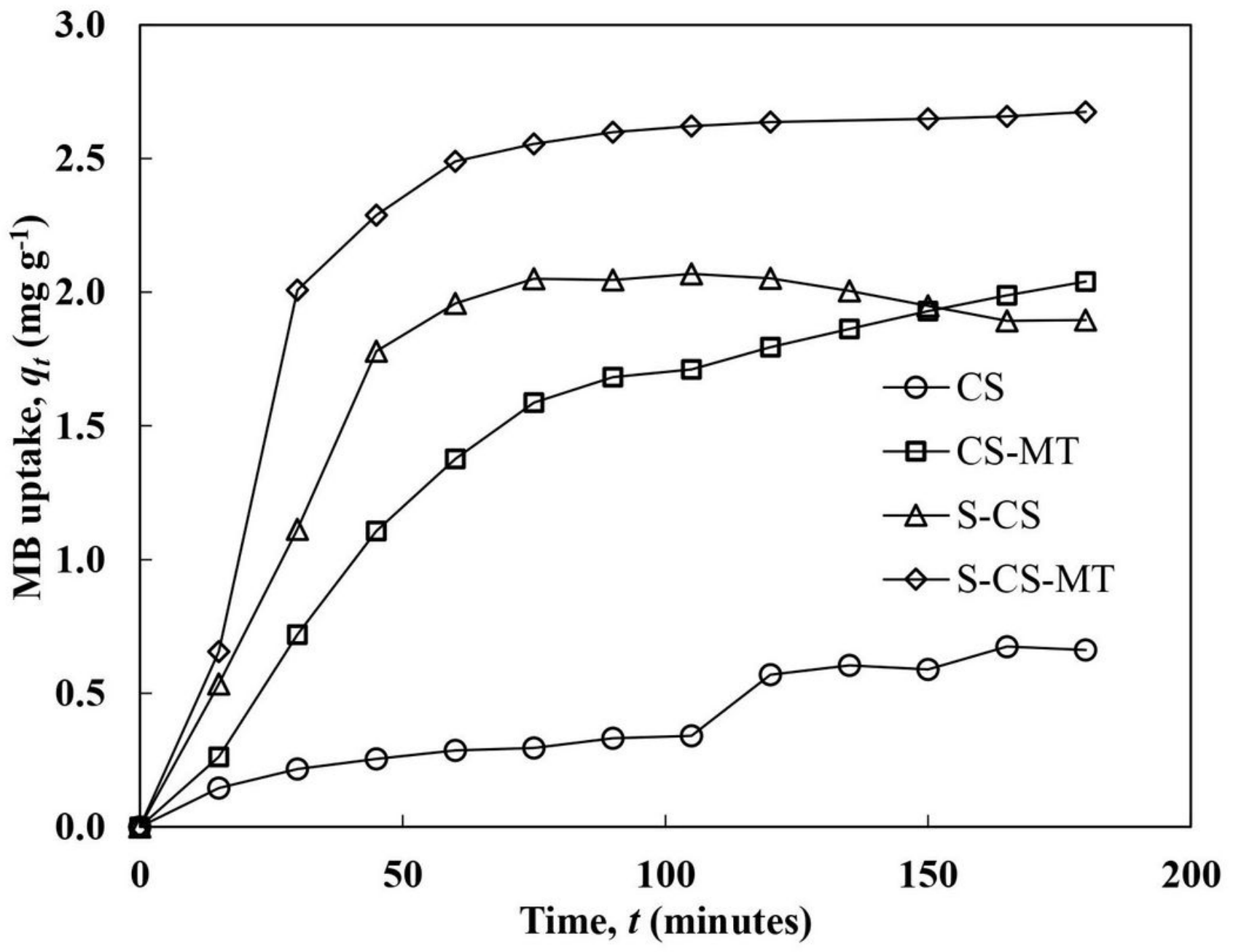

Figure 4

Comparison of MB uptake by CS, CS-MT, S-CS and S-CS-MT beads at an initial MB dye concentration of $10 \mathrm{mg} \mathrm{L}-1$ and temperature of $303 \mathrm{~K}$. 


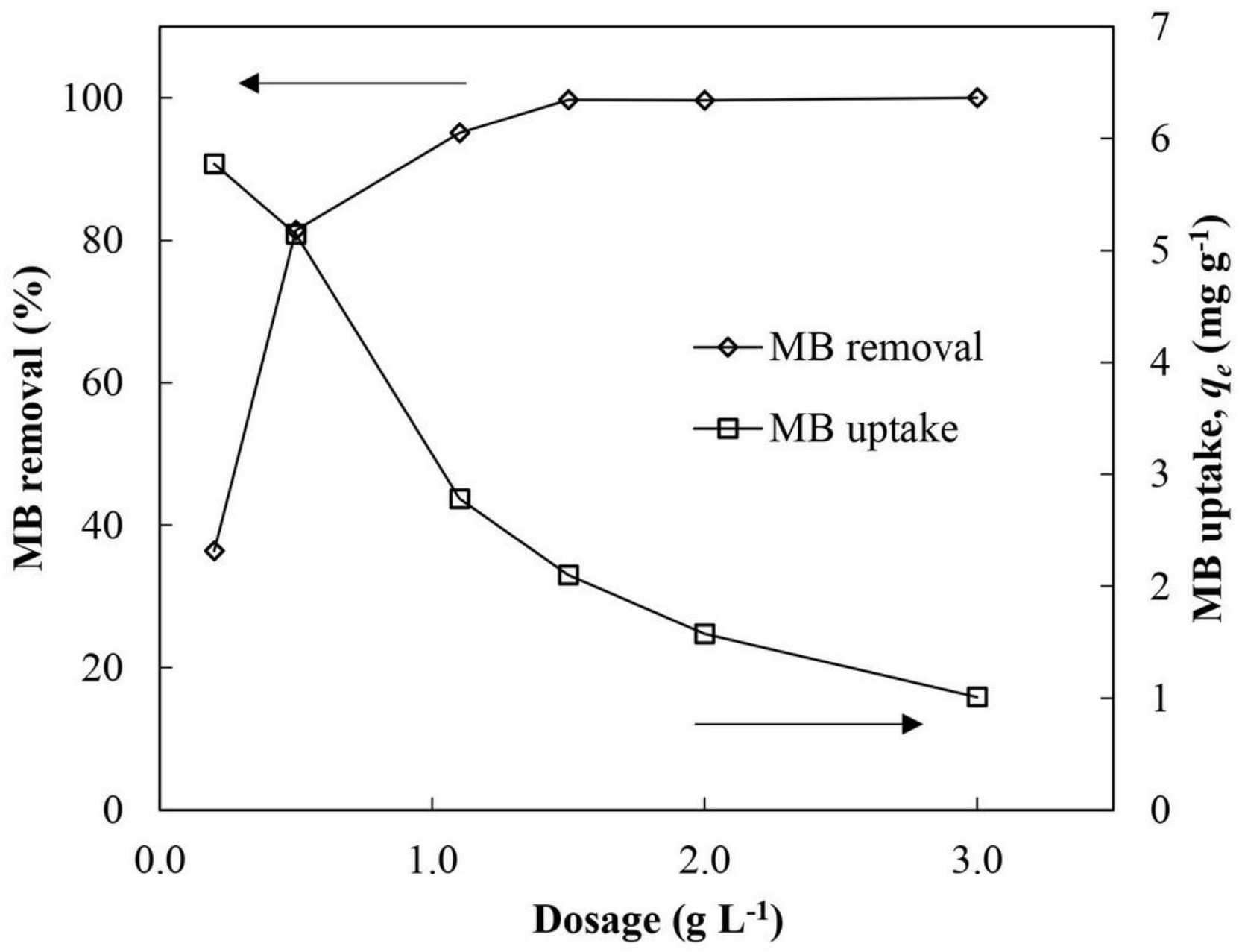

Figure 5

Effect of adsorbent dosage with an initial dye concentration of $10 \mathrm{mg} \mathrm{L}-1$ and temperature of $303 \mathrm{~K}$. 


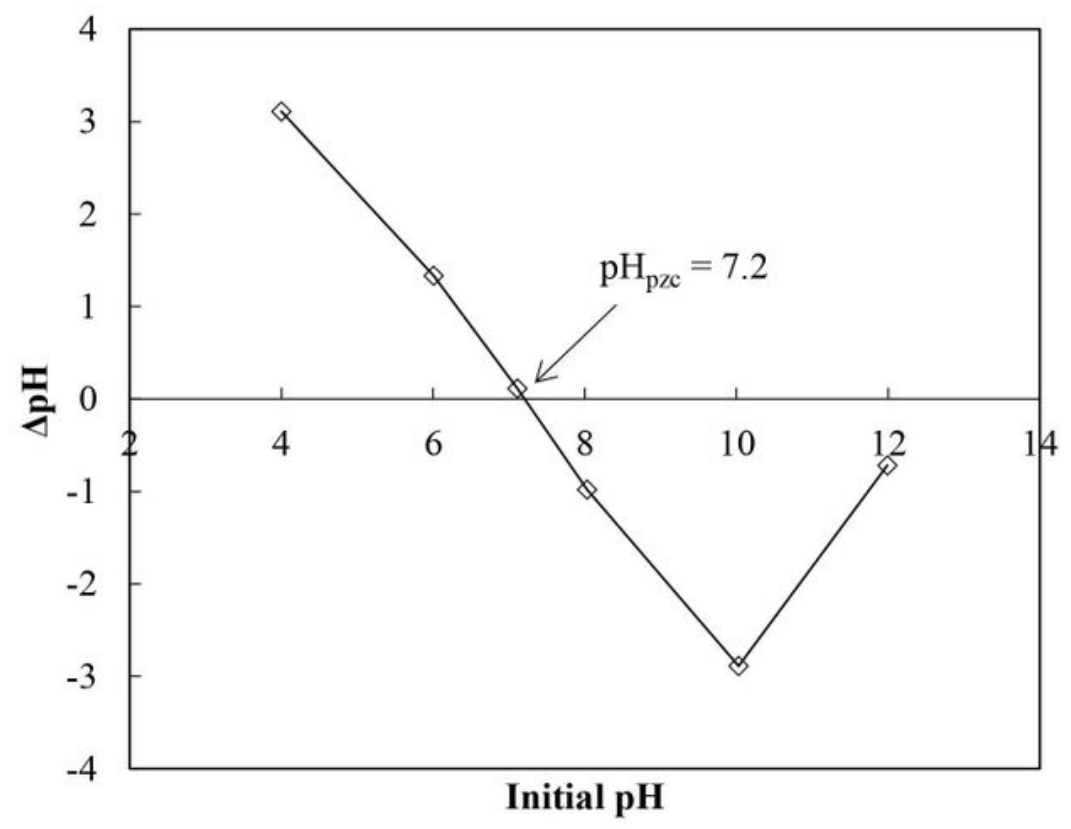

(a)

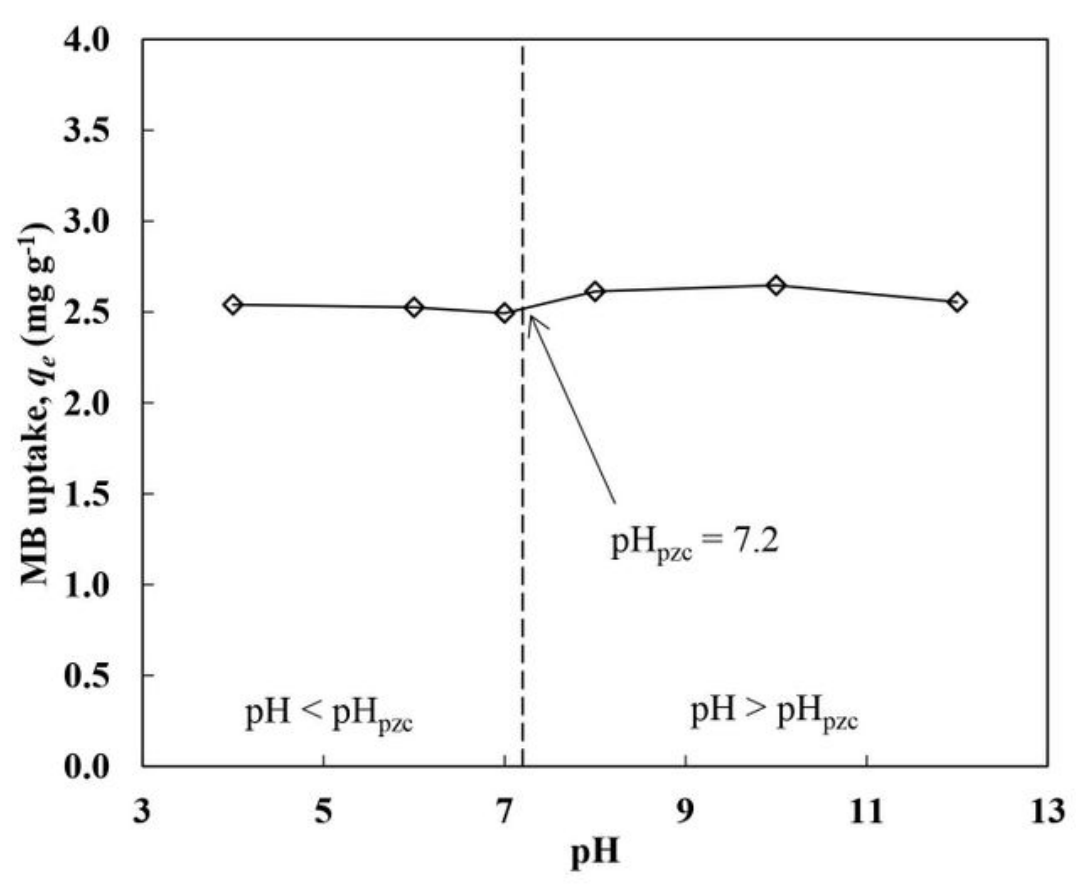

(b)

\section{Figure 6}

(a) $\mathrm{pH}$ point of zero charge ( $\mathrm{pHpzc}$ ) of S-CS-MT, and (b) effect of solution $\mathrm{pH}$ on MB adsorption with an initial dye concentration of $10 \mathrm{mg} \mathrm{L}-1$, dosage $1.1 \mathrm{~g} \mathrm{~L}-1$ and temperature of $303 \mathrm{~K}$. 


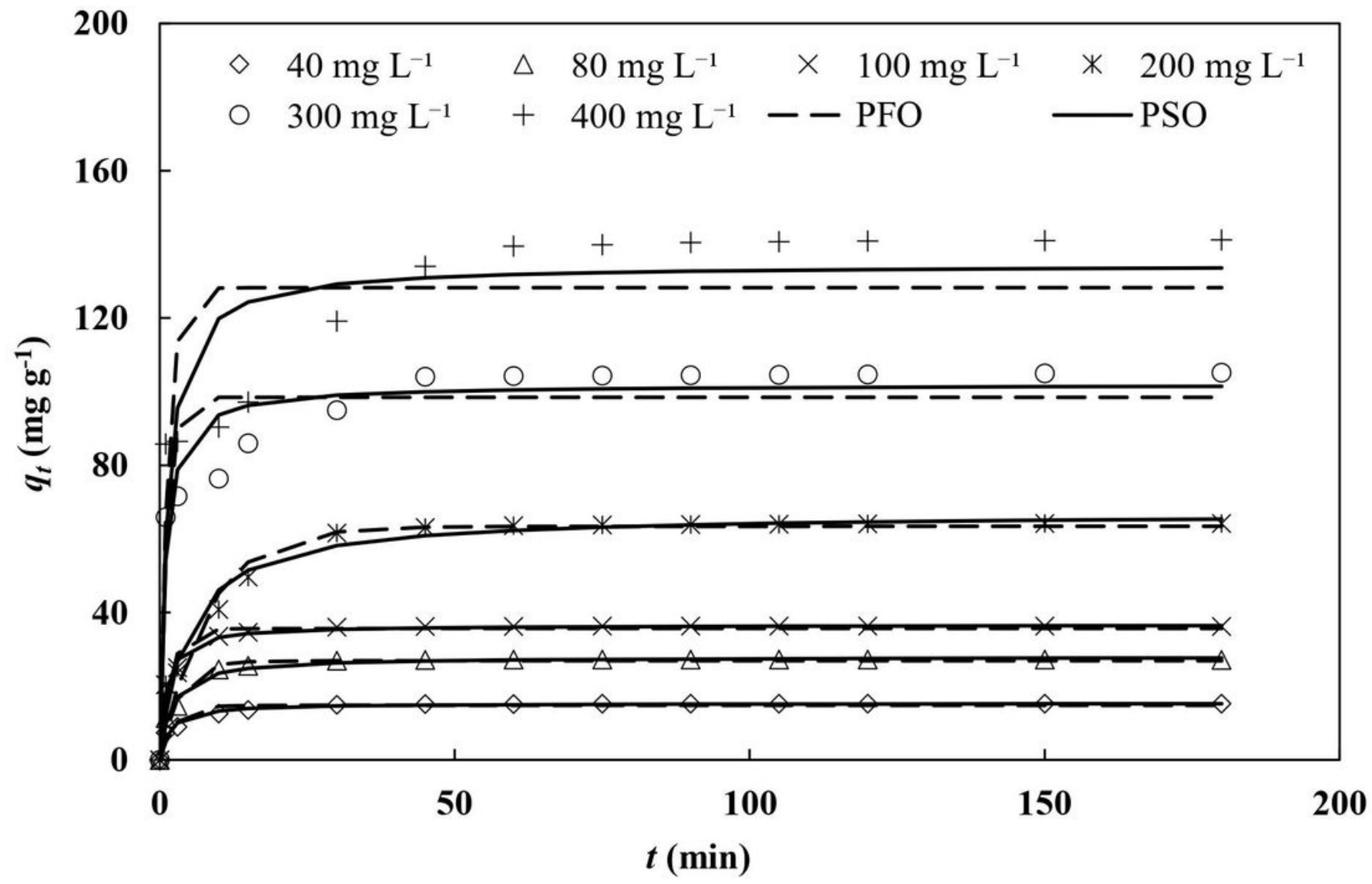

Figure 7

Non-linear plots of the PFO and PSO kinetic models for MB adsorption by S-CS-MT at $303 \mathrm{~K}$. 


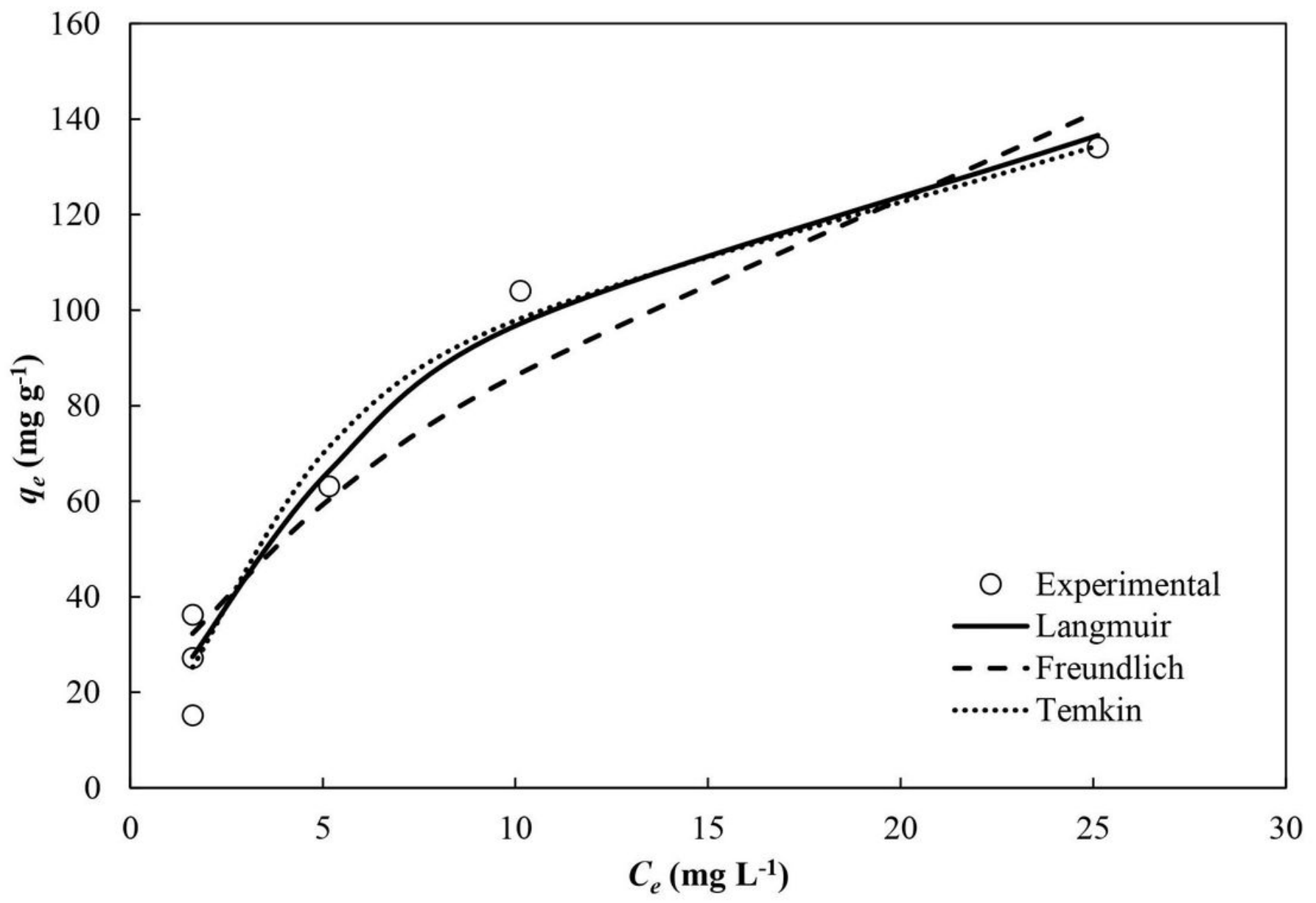

Figure 8

Adsorption isotherm plots of MB adsorption by S-CS-MT at $303 \mathrm{~K}$. 


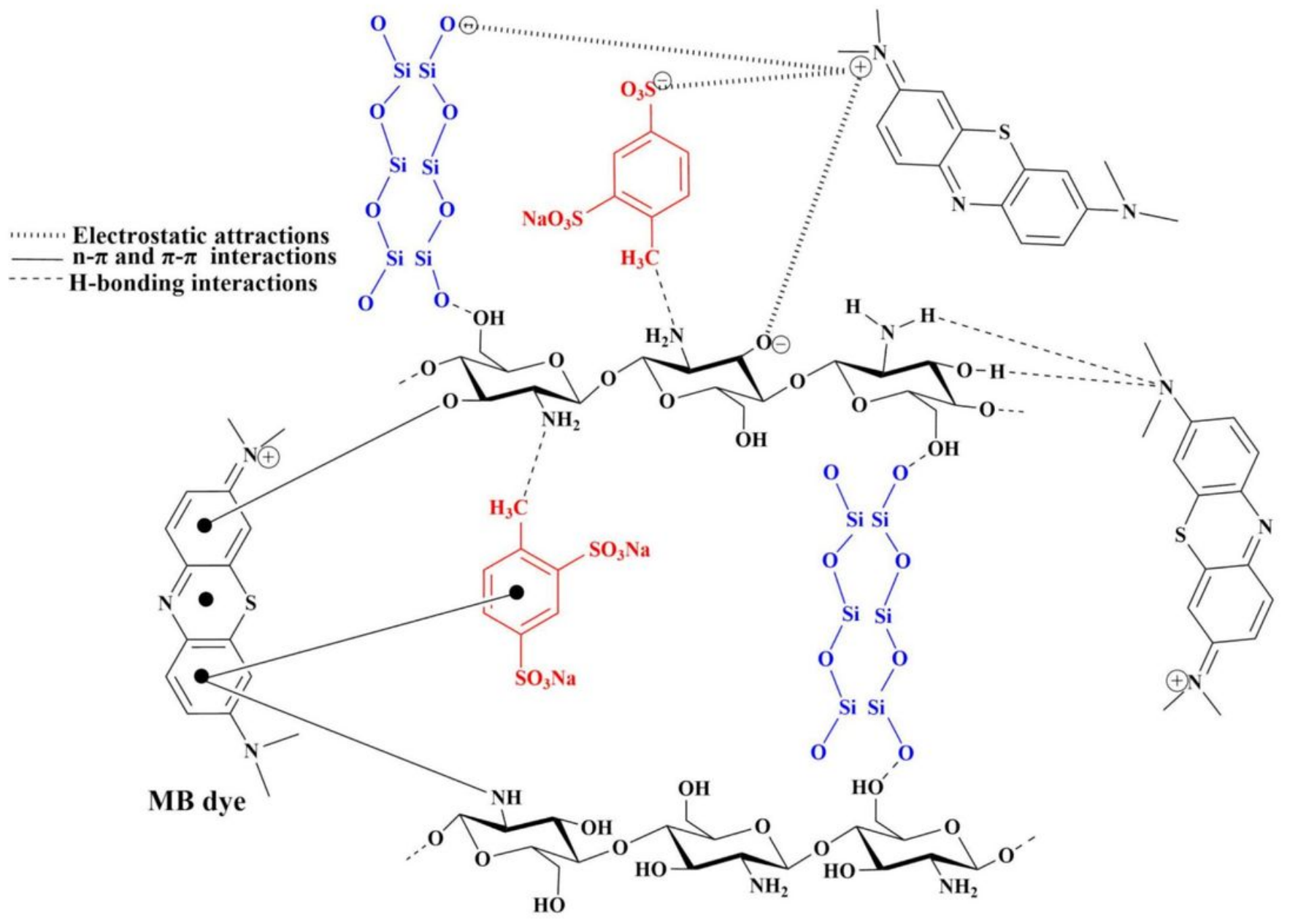

Figure 9

Illustration of the possible interactions between S-CS-MT and MB dye molecules 